\title{
O DESERTO DO SINAI
}

\section{THE SINAI DESERT}

Manu Marcus Hubner*

Resumo: Um lugar fantástico. Inóspito. Seco ao extremo. Cenário de uma das mais extraordinárias narrativas da Bíblia Hebraica: a outorga do Decálogo à humanidade. O deserto do Sinai é um local real, autêntico, por onde passaram os israelitas em suas jornadas em direção à Terra Prometida, assim como o profeta Elias, séculos mais tarde. Este artigo busca estudar o deserto do Sinai através da análise do significado do nome do local, dados bíblicos e talmúdicos, detalhes históricos, geográficos e arqueológicos.

Palavras-chave: Bíblia Hebraica. Sinai. Deserto. Israel. Êxodo.

Abstract: A fantastic place. Inhospitable. Extremely dry. The setting for one of the most extraordinary narratives in the Hebrew Bible: the granting of the Decalogue to humanity. The Sinai Desert is a real, authentic place where the Israelites passed on their journeys towards the Promised Land, as did the prophet Elijah centuries later. This article seeks to study the Sinai desert through the analysis of the meaning of the name of the place, Biblical and Talmudic data, historical, geographical and archaeological details.

Keywords: Hebrew Bible. Sinai. Desert. Israel. Exodus.

No quadragésimo quinto dia após uma saída dramática do Egito, devido às pragas que arrasaram o país e a subsequente destruição do exército egípcio durante o episódio da abertura das águas do mar, os israelitas chegaram ao Deserto do Sinai, para uma permanência aproximada de um ano.

Segundo o Livro do Êxodo, os israelitas ouviram a voz de Deus ao pé do Monte Sinai e receberam o Decálogo, evento decisivo para o nascimento da nação de Israel $^{1}$.

\footnotetext{
* Doutor em Letras pela Universidade de São Paulo.

Email: <marcushubner@gmail.com>.

${ }^{1}$ Segundo R. Sacks (2002, p. 144-147), o Êxodo foi apenas o prelúdio para o nascimento da nação de Israel. O evento decisivo aconteceu ao pé do Monte Sinai, com a voz de Deus e os Dez Mandamentos. No Sinai, os israelitas foram transformados de uma comunidade do destino ('am, "povo, nação, população, multidão", segundo BEREZIN, 2003, p. 503) em uma comunidade de fé ('edah, "comunidade, congregação, coletividade", ibid., p. 494), significando um corpo político sob a soberania de Deus, cuja constituição escrita era a Torá. "Atende e ouve, ó Israel! Hoje vieste a ser o povo do Eterno, teu Deus" (Dt 27:9). 
A experiência no Sinai ficou permanentemente incrustada na memória dos israelitas como um evento único, sem qualquer possibilidade de paralelo no curso de toda a história. Esta é a única narrativa em que o Deus de Israel - ele próprio, não um profeta ou um emissário - fez um pronunciamento público.

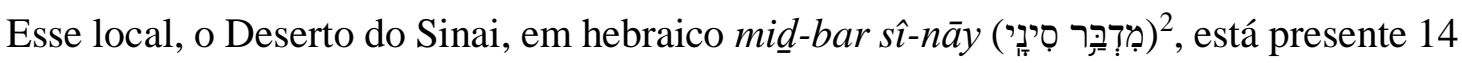

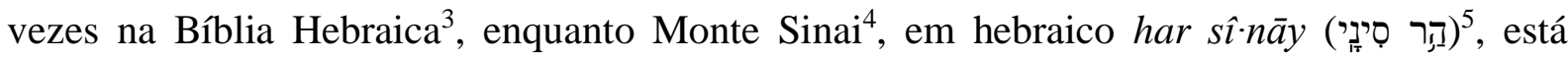

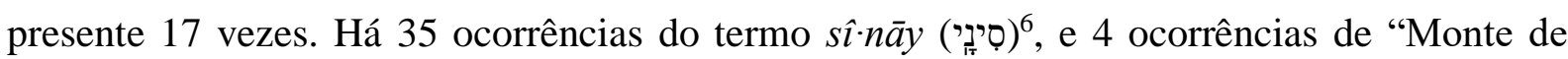
Deus", além de 17 ocorrências do nome alternativo ḥִ-rêb (זרב ${ }^{8}$. Por sua vez, a palavra

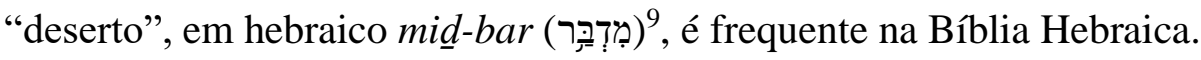

A palavra Sinai possui diversos prováveis significados:

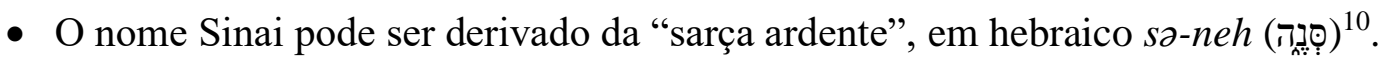

- Pode haver uma relação entre a palavra hebraica Sinai e o nome egípcio da cidade de Tell Farama, no norte do Sinai. O nome grego da cidade é Pelusium, que significa "cidade do barro", que pode ser derivado do termo egípcio sin, que significa "lama de argila" ${ }^{\prime 1}$.

\footnotetext{
${ }^{2}$ Ocorrências de Deserto do Sinai: Ex 19:1, 2; Lv 7:38; Nm 1:1, 19; 3:4, 14; 5; 9:1, 5; 10:12; 26:64; 33:15, 16.

${ }^{3}$ A Bíblia Hebraica, ou Tanach, é composta pelos 24 livros do Pentateuco, Profetas e Escritos. A Torá é o conjunto de livros que forma o Pentateuco. A palavra Torá é traduzida como "ensinamento, lei" por Jastrow (1903, p. 1657). As abreviações dos livros da Bíblia seguem o padrão da Bíblia de Jerusalém. A Bíblia utilizada para citações do Pentateuco neste trabalho será a A Bíblia Sagrada. Trad. João Ferreira de Almeida, edição revista e atualizada do software Bible Works.

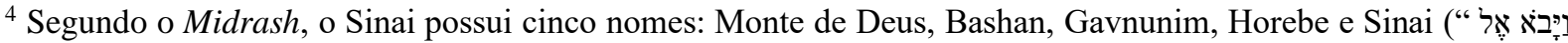
(") (Midrash Shemot Raba 2:4, disponível em: <https://www.sefaria.org/Shemot_Rabbah.2.4>, acesso em: 01/06/2021; versão similar em Midrash Shemot Raba 51:8).

Midrash é uma literatura judaica baseada na tradição oral, escrita como se fosse uma extensão das Escrituras, interpretando-as e extraindo ensinamentos e significados morais e religiosos não literais e não óbvios. A palavra Midrash significa "interpretação textual, estudo", segundo Jastrow (1903, p. 735) ou "exegese", segundo Neusner (1994, p. 223).

${ }^{5}$ Ocorrências de Monte Sinai: Ex 19:11, 18, 20, 23; 24:16; 31:18; 34:2, 4, 29, 32; Lv 7:38; 25:1; 26:46; 27:34; $\mathrm{Nm} 3: 1 ; 28: 6 ; \mathrm{Ne} 9: 13$.

${ }^{6}$ Ocorrências de Sinai: Ex 16:1; 19:1, 2; 19:11, 18, 20, 23; 24:16; 31:18; 34:2, 4, 29, 32; Lv 7:38; 25:1; 26:46; 27:34; Nm 1:1, 19; 3:1, 4, 14; 5; 9:1, 5; 10:12; 26:64; 28:6; 33:15, 16; Dt 33:2; Jz 5:5; Ne 9:13; Sl 68:9, 18

${ }^{7}$ Ocorrências de "Monte de Deus: Ex 4:27; 18:5; 24:13; S1 68:16.

${ }^{8}$ Ocorrências de Horebe: Ex 3:1; 17:6; 33:6; Dt 1:2, 6, 19; 4:10, 15; 5:2; 9:8; 18:16; 29:1; 1 Rs 8:9; 19:8; 2 Cr 5:10; Sl 106:19; Ml 4:4.

${ }^{9}$ Há 102 ocorrências da palavra mid bar, "deserto”, apenas no Pentateuco (B. Mazar, Enciclopedia Mikrait, 1982, vol. 4, p. 673-676).

${ }^{10}$ Cassia obovata, segundo Koehler \& Baumgartner (1985, p. 760). Ex 3:2-4: "E apareceu-lhe o anjo do Senhor em uma chama de fogo do meio duma sarça. Moisés olhou, e eis que a sarça ardia no fogo, e a sarça não se consumia; pelo que disse: Agora me virarei para lá e verei esta maravilha, e por que a sarça não se queima. $\mathrm{E}$ vendo o Senhor que ele se virara para ver, chamou-o do meio da sarça, e disse: Moisés, Moisés! Respondeu ele: Eis-me aqui".

${ }^{11}$ Gardiner (1918, p. 253-254).
} 
- A origem do termo Sinai pode estar relacionada com o nome da divindade lunar mesopotâmica Sin, uma palavra acádia ${ }^{12}$.

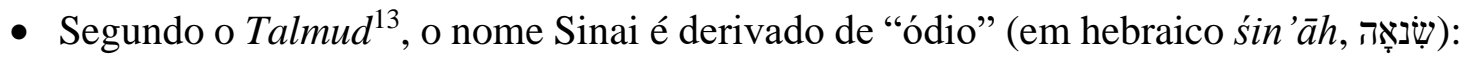

"Monte Sinai, porque dele desceu ódio para os idólatras"14.

- Segundo o Midrash, assim como o Talmud, o nome Sinai é derivado de "ódio" (em

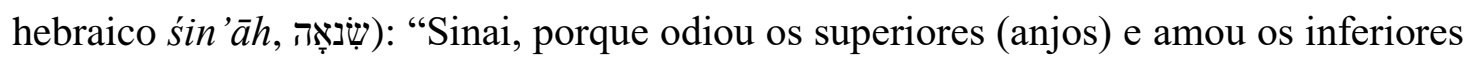
(homens)"'15, uma alusão ao fato de que a Torá foi outorgada aos homens, e não aos anjos.

O nome alternativo Horebe, por sua vez, possui os seguintes possíveis significados:

- Ruína, destruição, devastação ${ }^{16}$.

- Seco, árido ${ }^{17}$.

- Deserto, abandonado ${ }^{18}$.

- Segundo o Talmud, o nome Horebe é derivado de "desolação" (em hebraico ḥōrêbāh,

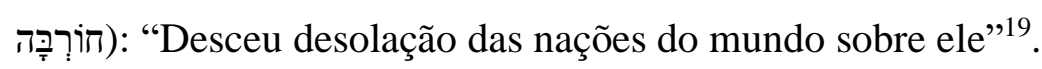

- Segundo o Midrash, o nome Horebe é derivado de "espada" (em hebraico hִe re “Horebe porque, porque nele foi dada a Torá que é chamada de 'espada', conforme foi dito, 'Estejam na sua garganta os altos louvores de Deus, e na sua mão espada de dois gumes' (S1 149:6)" ${ }^{\text {20. }}$

\footnotetext{
${ }^{12}$ Koehler \& Baumgartner (1985, p. 751).

${ }^{13}$ Talmud quer dizer "ensinamento, instrução, estudo" (Jastrow, 1903, p. 1672). É uma das obras fundamentais do judaísmo, sua "Lei Oral", que completa e explica a "Lei Escrita" - o Pentateuco (Hastings, 1909, p. 890). Compõese de duas partes: a Mishná e a Guemará, que foram compiladas, respectivamente, por volta dos anos 200 e 500 E.C.

Para todas as citações do Talmud será utilizado o software Judaic Classics: The Soncino Talmud. Versão 3.4. New York: Judaica Press, 1990, com tradução nossa.

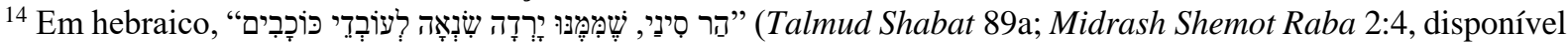
em: 〈https://www.sefaria.org/Shemot_Rabbah.2.4>, acesso em: 01/06/2021).

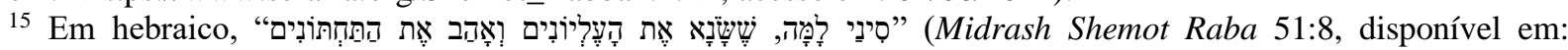
<https://www.sefaria.org/Shemot_Rabbah.51.8>, acesso em: 01/06/2021).

${ }^{16}$ Berezin (1995, p. 248); Jastrow (1903, p. 498). Pode também significar "queimado" ou "destruído". A mesma raiz pode ainda significar "espada" ou "faca" (Ibid.).

${ }^{17}$ Berezin (1995, p. 248); Jastrow (1903, p. 498).

${ }^{18}$ Levine (2000, p. 518).

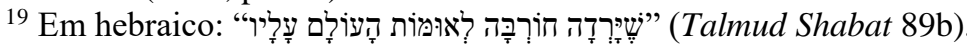

${ }^{20}$ Em hebraico, " (Midrash Shemot Raba 51:8, disponível em: 〈https://www.sefaria.org/Shemot_Rabbah.51.8>, acesso em: 01/06/2021).
} 


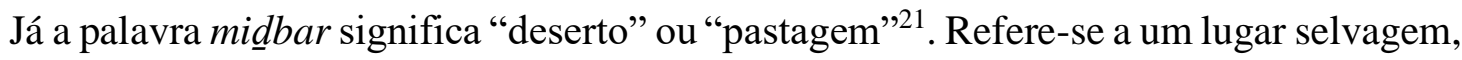
indomado pelo homem ${ }^{22}$ ou abandonado ${ }^{23}$, ou até mesmo impróprio para ser habitado ${ }^{24}$, mas pode significar também território de pasto $^{25}$ ou uma grande extensão de terreno ${ }^{26}$ eventualmente ocupada por nômades ${ }^{27}$.

Existem outras quatro palavras na Bíblia Hebraica comumente traduzidas como "deserto"28: שמממה (šmamah, "desolação") ישימון (yešimon, "desolação") "seca")"ציון (șayon, "terra seca")

O deserto, de forma geral, é lembrado como lugar ruim ${ }^{33}$, onde não há árvores frutíferas, nem é possível de se semear ${ }^{34}$, mas há animais malvados e peçonhentos, cobras e escorpiões ${ }^{35}$. Uma terra desolada, onde não passam nem moram pessoas ${ }^{36}$, e aquele que se arriscar está sujeito à fome e à sede ${ }^{37}$. Os habitantes do deserto estão sujeitos a privações ${ }^{38}$, e se empobrecem fora dos assentamentos. As Escrituras também descrevem o deserto como local de escuridão ${ }^{39}$ e sombra da morte ${ }^{40}$. Do deserto temível ${ }^{41}$ se ouvem os uivos ${ }^{42}$ e de lá vem o vento da

${ }^{21}$ Jastrow (1903, p. 731).

${ }^{22}$ Alter e Kermode (1997, p. 626-9).

${ }^{23}$ Hirsch (2002).

${ }^{24}$ B. Mazar (Enciclopedia Mikrait, 1982, vol. 4, p. 673-676); Brown, Driver \& Briggs (1907, p. 184-185).

${ }^{25}$ B. Mazar (Enciclopedia Mikrait, 1982, vol. 4, p. 673-676); Brown, Driver \& Briggs (1907, p. 184-185); Hirsch (202); Jastrow (1903, p. 731). Segundo Alter e Kermode (1997, p. 626-9), midbar significa, principalmente, terra de pastagem seca onde há vegetação esparsa.

${ }^{26}$ Brown, Driver \& Briggs (1907, p. 184-185).

${ }^{27}$ Hirsch (2002).

${ }^{28}$ Brown, Driver \& Briggs (1907, p. 445, 851, 1031); Hirsch (2002); Jastrow (1903, p. 1597).

${ }^{29}$ Is $64: 9 ;$ Jr $12: 10$.

${ }^{30}$ Dt 32:10; S1 78:40.

${ }^{31}$ Is $41: 18$; Os 2:5.

${ }^{32}$ Is $25: 5,32: 2$.

33 "E por que nos fizestes subir do Egito, para nos trazer a este mau lugar? lugar onde não há semente, nem figos, nem vides, nem romãs, nem mesmo água para beber" (Nm 20:5).

34 "Vai, e clama aos ouvidos de Jerusalém, dizendo: Assim diz o Senhor: Lembro-me, a favor de ti, da devoção da tua mocidade, do amor dos teus desposórios, de como me seguiste no deserto, numa terra não semeada" (Jr 2:2).

35 "[...] que te conduziu por aquele grande e terrível deserto de serpentes abrasadoras e de escorpiões" (Dt 8:15).

36 "Eles não perguntaram: Onde está o Senhor, que nos fez subir da terra do Egito? que nos enviou através do deserto, por uma terra de charnecas e de covas, por uma terra de sequidão e densas trevas, por uma terra em que ninguém transitava, nem morava?" (Jr 2:6).

37 "Andaram desgarrados pelo deserto, por caminho ermo; não acharam cidade em que habitassem. Andavam famintos e sedentos; desfalecia-lhes a alma" (Sl 107:4-5).

38 "De míngua e fome emagrecem; andam roendo pelo deserto, lugar de ruínas e desolação" (Jó 30:3).

39 “...porventura tenho eu sido para Israel um deserto? Ou uma terra da mais espessa escuridão?” (Jr 2:31).

40 "Que nos guiou pelo deserto, por uma terra de charnecas, e de covas, por uma terra de sequidão e sombra de morte" (Jr 2:6).

41 “...e andamos por todo aquele deserto grande e temível que vistes..." (Dt 1:19); "Quem te conduziu pelo deserto grande e temível..." (ibid. 8:15).

42 "Proporcionou-lhe as necessidades, na terra do deserto, e no ermo solitário cheio de uivos..." (ibid. 32:10). 
destruição $0^{43}$. O deserto também pode estar em oposição ao Éden ${ }^{44}$, ou ao abismo (ermo) ${ }^{45}$. Sendo o deserto claramente considerado ruim, é como se fosse um modelo de coisas ruins ${ }^{46}$.

Apesar da conotação negativa atribuída ao deserto, há, em contraste, uma relação positiva nas lembranças do período de quarenta anos em que os filhos de Israel perambularam pelo deserto, guiados por Deus, que os protegeu e salvaguardou de todas as intempéries do caminho: "Achou-o numa terra deserta, e num erma de solidão e horrendos uivos; cercou-o de proteção; cuidou dele, guardando-o como a menina do seu olho" (Dt 32:10). A lembrança é adornada com sentimentos de devoção, amor e subordinação: “Assim diz o Senhor: Lembrome, a favor de ti, da devoção da tua mocidade, do amor dos teus desposórios, de como me seguiste no deserto, numa terra não semeada" (Jr 2:2). Israel é cuidadosamente cultivado e cuidado: "Achei a Israel como uvas no deserto, vi a vossos pais como a fruta temporã da figueira no seu princípio..." (Os 9:10). E é exatamente no deserto que um contrato é celebrado entre Deus e o povo de Israel, a Torá, com direitos, deveres e até mesmo punições ${ }^{47}$.

O deserto das jornadas dos israelitas pode ser visto como um mundo invertido ${ }^{48}$, cuja entrada e saída só são acessíveis através da abertura das águas ${ }^{49}$, e onde o pão, que deveria vir do trigo plantado na terra, cai do céu ${ }^{50}$ e a água, que deveria cair do céu em forma de chuva, vem do chão, da pedra ${ }^{51}$. O chão do Sinai é literalmente comparado ao céu, embelezando a teofania: "e debaixo de seus pés havia como que uma calçada de pedra de safira, que parecia com o próprio céu na sua pureza" (Ex 24:10). O Sinai pode, portanto, ser um ponto de ligação

43 "Como os tufões de vento passam por meio da terra do sul, assim do deserto virá, da terra horrivel” (Is 21:1); “...virá o vento oriental, vento do Senhor, subindo do deserto, e secar-se-á a sua nascente, e se estancará a sua fonte..." (Os 13:15); “e eis que sobrevindo um grande vento de além do deserto, deu nos quatro cantos da casa, e ela caiu sobre os mancebos, de sorte que morreram..." (Jó 1:19).

44 “....e fará o seu deserto como o Éden, e a sua solidão como o jardim do Senhor...” (Is 51:3); “.... a terra diante dele é como o jardim do Édem mas atrás dele um desolado deserto..." (J1 2:3).

45 “...ermo solitário cheio de uivos” (Dt 32:10).

${ }^{46}$ B. Mazar (Enciclopedia Mikrait, 1982, vol. 4, p. 673-676). Cf. "Melhor é morar numa terra deserta do que com a mulher rixosa e iracunda" (Pr 21:19).

47 "Estes, pois, são os mandamentos, os estatutos e os preceitos que o Senhor teu Deus mandou ensinar-te, a fim de que os cumprisses na terra a que estás passando: para a possuíres; para que temas ao Senhor teu Deus, e guardes todos os seus estatutos e mandamentos, que eu te ordeno, tu, e teu filho, e o filho de teu filho, todos os dias da tua vida, e para que se prolonguem os teus dias" (Dt 6:1-2).

48 "O deserto é o Outro Mundo. (...) Nesse outro mundo tudo acontece às avessas. O pão celestial cai do céu como chuva; a água celestial não cai como chuva, mas emerge de uma rocha. (...) Para entrar neste outro mundo sagrado, pessoas comuns precisam de intervenção Divina pela qual os limites de água sejam tornados transponíveis" (Alter e Kermode, 1997, p. 626-9).

${ }^{49} \mathrm{O}$ mar se abre para a passagem dos israelitas ao saírem do Egito ("Então Moisés estendeu a mão sobre o mar; e o Senhor fez retirar o mar por um forte vento oriental toda aquela noite, e fez do mar terra seca, e as águas foram divididas. E os filhos de Israel entraram pelo meio do mar em seco; e as águas foram-lhes qual muro à sua direita e à sua esquerda", Ex 14:21-22). O rio Jordão se abre para a passagem dos israelitas ao entrarem em Canaã ("Os sacerdotes que levavam a arca do pacto do Senhor pararam firmes em seco no meio do Jordão, e todo o Israel foi passando a pé enxuto, até que todo o povo acabou de passar o Jordão”, Js 3:17).

50 "Eis que vos farei chover pão do céu" (Ex 16:4).

51 “...ferirás a rocha, e dela sairá água para que o povo possa beber” (Ex 17:6). 
intangível entre o céu e a terra: "Uma ponte de terra para as pessoas que se deslocam de um continente para outro, sim, mas também uma ponte metafísica entre o homem e Deus" ${ }^{\$ 5}$.

O historiador Josefo considera o Deserto do Sinai assustador e inacessível ${ }^{53}$, enquanto estudiosos modernos destacam a extrema aridez ${ }^{54}$ e a impossibilidade de um grupo numeroso de pessoas e rebanhos habitarem a região ${ }^{55}$.

Na região centro-sul da península do Sinai, as temperaturas médias, mínima e máxima, são $-5^{\circ} \mathrm{C}$ e $40,5^{\circ} \mathrm{C}$. Chuvas são raras e irregulares, a média anual está abaixo de 0,6 milímetros. Uma pequena parte da neve que cobre alguns picos aumenta os estoques de água, e há também reservatórios subterrâneos suficientemente próximos à superfície para serem interceptados. Piscinas naturais também se formam esporadicamente com água das chuvas, ao longo dos wadis $^{56}$, e estas águas podem durar meses. Algumas vezes, as águas de reservatórios subterrâneos correm para os wadis, fazendo com que alguns oásis se mantenham. Há vegetação rasteira, típica do deserto. O Sinai central é chamado em Árabe Badyat el-Tih, “o Deserto dos Viajantes”, uma área plana de calcário e areia, imprópria para qualquer tipo de plantação. Até a vegetação selvagem luta para sobreviver devido à escassez de água ${ }^{57}$. As condições naturais do sul do Sinai tornam impossível a sobrevivência de um grande número de pessoas durante longos períodos, por falta de alimentos para os homens e os animais ${ }^{58}$.

A Península do Sinai pertence, atualmente, ao Egito. Porém, não há evidências de presença egípcia na região centro-sul do Sinai em época alguma da história do antigo Egito ${ }^{59}$. O Sinai não era considerado pelos faraós como parte do Egito. O Egito propriamente dito, a "Terra Negra", era composto pelo Vale do Nilo e pelo Delta, enquanto as áreas externas ou desérticas eram chamadas de "Terra Vermelha" ou "Terra Estrangeira"60. De fato, não havia

\footnotetext{
52 TEAGUE (2009, p. 106-8).

53 “O Sinai supera em altura todos os montes das províncias vizinhas e está tão cheio de escarpas por todos os lados que não somente é muito dificultoso lá subir como também não se poderia contemplá-lo sem temor, pois é crença comum que Deus lá habita, e este lugar mostra-se assustador e inacessível” (JOSEFO, 2008, p. 164).

54 “O país é quase sem água, com a exceção de algumas fontes nos wadis maiores; mas mesmo aqui a água só pode ser obtida por raspagem de pequenos buracos no solo e enfardando para fora com a mão. Tudo o que é obtido pelo processo é uma solução amarelada que atrapalha todas as tentativas de filtragem; [...] Natureza totalmente árida do solo" (PALMER, 1872, p. 234).

55 “O planalto de Tih [planalto central da Península do Sinai] é deprimente ao extremo. Durante a nossa viagem através dele nós não vimos uma única tenda ou um animal pastando. O itinerário provável dos hebreus era através deste deserto. Isto parece-me ser absolutamente impossível, pois as pessoas não podiam atravessar este deserto com rebanhos e manadas" (PRENTICE, 1913, p. 239).

56 "Riacho, somente em período de chuva" (BEREZIN, 2003, p. 201).

${ }^{57}$ Beit-Arieh (1988, p. 35).

${ }^{58}$ Har-El (1983, p. 372-373).

${ }^{59}$ Beit-Arieh (1988, p. 36).

${ }^{60}$ Segundo Espinel (2006, p. 82), a ideia de "território estrangeiro" é representada pelo termo em egípcio antigo ḩ3st, que significa "deserto, montanha, deserto montanhoso, savana ou espaço topograficamente acidentado". O termo é utilizado para designar tanto o deserto egípcio, quanto wadis e oásis - terra sem dono ou jurisdição.
} 
um nome egípcio específico para toda a Península do Sinai. Parece que o nome Sinai também só se aplicava a uma área limitada, e não a península completa. Como e quando o nome Sinai passou a denominar toda a região é desconhecido. Para os escritores clássicos, Arábia é o nome dado para o Sinai. Possivelmente durante o período bizantino, o nome bíblico Sinai substituiu o nome Arábia e se estendeu para toda a península ${ }^{61}$.

O Deserto do Sinai é a décima-segunda estação onde acamparam os israelitas após a saída do Egito ${ }^{62}$. Segundo a cronologia intrabíblica, a chegada ao Sinai ocorreu no $45^{\circ}$ dia da saída do Egito, que seria, de acordo com o calendário hebraico, o dia 01 do mês de Sivan do ano de 2448 , um domingo ${ }^{63}$. Os israelitas permaneceram por cerca de um ano no deserto do Sinai $^{64}$. Os Dez Mandamentos foram outorgados no dia 06 (sábado) do mês de Sivan do ano de $2448^{65}$ e o Tabernáculo foi erguido no dia 25 do mês de Kislev ou no dia 01 do mês de Adar do ano de $2449^{66}$. A saída dos israelitas do Sinai para Kibrot-Hataavá, a estação seguinte, ocorreu no $389^{\circ}$ dia da saída do Egito, que corresponde a 1 ano, 1 mês e 5 dias da saída do Egito, no dia 20 do mês de Iyar do ano de $2449^{67}$.

Neste local, ocorreram muitos fatos relevantes:

- Visita de Jetró, sogro de Moisés, e o reencontro com sua família (Ex 18).

- Escolha de líderes - juízes e guardas (Ex 18:21-26).

- A outorga dos Dez Mandamentos (Ex 19:16-20:23).

- Moisés permanece no topo da montanha por três períodos de 40 dias cada. Primeiro período: subida em 7 de Sivan (Ex 24:12-18), quando Moisés foi buscar os

\footnotetext{
${ }^{61}$ Hoffmeier (2005, p. 37-40).

${ }^{62} \mathrm{Nm}$ 33:15; Hubner (2016, p. 88).

${ }^{63}$ Baal HaTurim (R. Jacob ben Asher, séc. 13-14, comentário sobre Ex 19:1, em: Mikraot Guedolot Meorot, 1995, Vol. 2, p. 439); Deutsch (2006, p. 135); Kantor (2007, p. 77).

64 "Assim, você diz que eles passaram doze meses menos dez dias em Horeb, pois no primeiro dia [do mês de] Sivan, eles acamparam lá, e não viajaram até o vigésimo dia de Iyyar do ano seguinte" (Rashi, Rabi Shlomo Itzchaki, França 1040-1105 E.C., comentário sobre Números 10:11, em: Mikraot Guedolot Meorot, 1995, Vol. 4, p. 176, tradução nossa).

${ }^{65}$ Deutsch (2006, p. 139); Kantor (2007, p. 77).

${ }^{66}$ Kantor (2007, p. 77).

${ }^{67}$ Midrash Seder Olam 8 em Kaplan (1981, p. 845); Midrash Mechilta e Lekach Tov, comentário sobre Ex 19:2 em Deutsch (2006, p. 141). Segundo Deutsch, os filhos de Israel permaneceram no Sinai durante 344 dias. Se ficassem mais dez dias, teriam permanecido por um ano completo, de 01 de Sivan de 2448 a 01 de Sivan de 2449, conforme o comentário de Rashi sobre Números 10:11: "Assim, você diz que eles passaram doze meses menos dez dias em Horeb, pois no primeiro dia [do mês de] Sivan, eles acamparam lá, e não viajaram até o vigésimo dia de Iyyar do ano seguinte." (Rashi, comentário sobre Números 10:11, em: Mikraot Guedolot Meorot, 1995, Vol. 4, p. 176). Observação: um ano judaico/lunar tem 354 dias, segundo The Jewish Calendar, in Web Exhibits, disponível em: <http://www.webexhibits.org/calendars/calendar-jewish.html>, acesso em: 24/08/2009. Como os israelitas chegaram ao Sinai no $45^{\circ}$ dia após a saída do Egito, e permaneceram por 344 dias, o dia da saída do Sinai é o $389^{\circ}$ dia desde a saída do Egito. Como o calendário judaico possui 354 dias, 389 dias correspondem a 1 ano e 35 dias, ou seja, aproximadamente 1 ano, 1 mês e 5 dias.
} 
ensinamentos da Torá, e descida em 17 de Tamuz (Ex 32:15), dia do pecado do bezerro de ouro; segundo período: subida em 18 de Tamuz e descida em 29 de Av (Ex 32:30-31), quando Moisés reza pelo perdão aos israelitas; terceiro período: subida em 30 de Av (Ex 34:4), quando Moisés esculpe as novas “tábuas da lei”, e descida em 10 de Tishrê (Ex 34:29), quando os israelitas são finalmente perdoados, e este dia se torna o "dia do perdão" no calendário judaico ${ }^{68}$.

- O pecado do bezerro de ouro (Ex 32:1-6).

- Construção do Tabernáculo e de seus utensílios (Ex 39:32-43).

- Primeiro censo e escolha dos líderes das Tribos (Nm 1).

- Organização do acampamento de acordo com as Tribos (Nm 2).

- Primeira Páscoa no deserto (Nm 9:1-5).

Sinai (Horebe) é também o lugar para o qual o profeta Elias, partindo de Berseba, caminhou em jejum por quarenta dias e quarenta noites ${ }^{69}$. E lá encontrou um forte vento, terremoto e fogo, além da revelação divina ${ }^{70}$.

O Deserto do Sinai ocupa a região centro-sul da Península do Sinai. Porém, a localização exata do monte sob o qual os israelitas ouviram a voz de Deus não é comprovada. A Bíblia Hebraica fornece referências pouco elucidativas sobre a localização do Monte Sinai: três dias de distância do Egito (Ex 5:3, 8:21, 16:22, Nm 10:33, 33:8); onze dias de distância de CadesBarnéa (Dt 1:2); quarenta dias de distância de Berseba (1 Rs 19:3, 8). Arqueólogos, historiadores e outros estudiosos do assunto divergem sobre sua localização. As possibilidades mais comuns são:
- Jebel Halal ${ }^{71}$.
- Jebel Musa ${ }^{72}$.

68 Midrash Tanchuma 21:1, disponível em: <http://www.sefaria.org/Midrash_Tanchuma.1.21>, acesso em: 10/11/14; Kantor (2007, p. 77). Sobre o “dia do perdão", ou, em hebraico, Yom Kipur: Lv 16:29-31; 23: 26-32; Nm 29:7-11.

69 "Levantou-se, pois, e comeu e bebeu; e com a força desse alimento caminhou quarenta dias e quarenta noites até Horebe, o monte de Deus. Ali entrou numa caverna, onde passou a noite" (1 Rs 19:8-9).

701 Rs 19:11-18.

${ }^{71}$ Albright (1950, p. 1-14); Jarvis (1932, p. 166). Caso os israelitas estivessem em uma rota pelo norte da Península do Sinai, Jebel Halal poderia ser o Monte Sinai bíblico. Porém, Cades-Barnéa fica a menos de cinquenta quilômetros de distância do monte, ou seja, muito menos do que os onze dias de distância registrados pela Bíblia Hebraica (Dt 1:2).

${ }^{72}$ Aharoni (1979, p. 198-9); Bright (2000, p. 125); Brown, Driver \& Briggs (1907, p. 696); Davies (2009, p. 6369); Kitchen (2006, p. 270). Próximo ao monte, localiza-se o Mosteiro Ortodoxo de S. Catarina, construído no sexto século E.C., sob ordens do imperador romano Justiniano (482-565 E.C.). Segundo o historiador Procópio de 
- Jebel Serbal ${ }^{73}$.

- Jebel Safsafah ${ }^{74}$.

- Jebel Sin Bisher ${ }^{75}$.

- Har Karkom ${ }^{76}$.

- Jebel El Lawz ${ }^{77}$, na Península Arábica.

Cesareia (aprox. 500-565 E.C.), “O imperador Justiniano construiu uma igreja para eles... Ele construiu esta igreja, não no topo da montanha, mas muito mais abaixo. Pois é impossível para um homem passar a noite no cume, uma vez que estrondos constantes de trovões e outras manifestações terríveis do poder divino são ouvidos à noite, causando terror no corpo e na alma do homem. Foi naquele lugar, dizem eles, que Moisés recebeu as leis de Deus e as publicou. E na base da montanha este imperador construiu uma fortaleza muito vigorosa e lá estabeleceu uma considerável guarnição de tropas..." (Procopius, Vol. 7, 1971, p. 357, tradução nossa). Segundo Bright, Jebel Musa é o Monte Sinai devido à proximidade com as famosas minas de cobre de Serābît el-Khâdim. Isso está de acordo com a tradição de que parentes de Moisés, chamados Quenitas (“artistas, ferreiros, ourives", segundo Jastrow, 1903, p. 1363) (Jz 1:16), sejam encontrados na área (Bright, 2000, p. 125).

${ }^{73}$ Hoffmeier (2005, p. 146-148); Kitchen (2006, p. 270); Petrie (1906, p. 252). Segundo Hoffmeier, Jebel Serbal está isolado de outras montanhas e possui uma área extensa para acampamentos, além da proximidade do oásis do Wadi Feiran (Hoffmeier, 2005, p. 147). Petrie acredita que esta proximidade de fontes de água é que determina a rota através do deserto, e o nome Serb-Baal significa “os palmeirais de Baal”, ou seja, a montanha já seria sagrada, estaria associada a uma divinidade (Petrie, 1906, p. 246, 252).

${ }^{74}$ Hoffmeier (2005, p. 144-146); Palmer (1872, p. 97-100). Segundo Hoffmeier, há uma fonte de água pura a poucos minutos de caminhada e uma planície em frente ao monte em forma de anfiteatro chamada de er-Râhah, própria para um acampamento prolongado (Hoffmeier, 2005, p. 144-145).

${ }^{75}$ Cole (2000, p. 523); Har-El (1983, p. 415-420). Har-El acredita que Jebel Sin Bisher está em conformidade com as distâncias previstas na Bíblia Hebraica, além do significado expressivo do seu nome, "o relato da lei" ou "as leis do homem". Outro significado possível deste nome seria "dente humano". Além disso, a parte sul do Sinai não se localiza na rota para Canaã e nem para Cadesh-Barnea; nem mesmo para Midian, para onde Moisés se dirigiu ao fugir do Egito (Ex 2:15) e de onde voltou (Ex 4:20). O Monte Sinai deve se localizar próximo ao Egito, devido à expressão recorrente "três dias de viagem" (Ex 5:3, 8:21, 16:22, Nm 10:33, 33:8). As minas de cobre e turquesa do império egípcio se localizavam no sul do Sinai, e seria ilógico para os israelitas entrarem em contato com o exército egípcio, que cuidava das minas. Dt 1:2 registra que são onze dias de viagem entre Horebe e CadeshBarnea, porém a distância até o sul do Sinai é bem maior, mais de 350 quilômetros. Jebel Sin Bisher é a única montanha que preserva o nome Sinai na forma "Sin" (Har-El, 1983, p. 372-373, 415-420).

76 Anati (2001). Har Karkom era um centro de culto e uma montanha sagrada especialmente entre 2350-2000 A.E.C., e a topografia e as evidências arqueológicas parecem refletir a localização e o caráter do Monte Sinai.

${ }^{77}$ Cornuke \& Halbrook (2000, p. 170-180); Wyatt \& Fasold (1994). Cornuke \& Halbrook identificam a Arábia da afirmação de Paulo em Gálatas 4:25 ("monte Sinai na Arábia”) com a atual Arábia Saudita. Além disso, Jebel elLawz tem seu topo negro, o que pode ser uma consequência do fogo descrito em Ex 19:18: "Nisso todo o monte Sinai fumegava, porque o Senhor descera sobre ele em fogo; e a fumaça subiu como a fumaça de uma fornalha, e todo o monte tremia fortemente" (Cornuke \& Halbrook, 2000, p. 179-180). Wyatt \& Fasold, por sua vez, encontraram peças de carruagens egípcias no Golfo de Áquaba, bem a oeste de Jebel el-Lawz, assim como pilares de pedra, altares e inscrições em hebraico arcaico, além de petróglifos de vaca e touro. Encontraram também minúsculas manchas de ouro incrustadas em toda a área desgastada do topo da rocha, o que acreditam ser os restos moídos do bezerro de ouro, cf. Ex 32:20: "Então tomou o bezerro que tinham feito, e queimou-o no fogo; e, moendo-o até que se tornou em pó, o espargiu sobre a água, e deu-o a beber aos filhos de Israel" (Wyatt \& Fasold, 1994). 


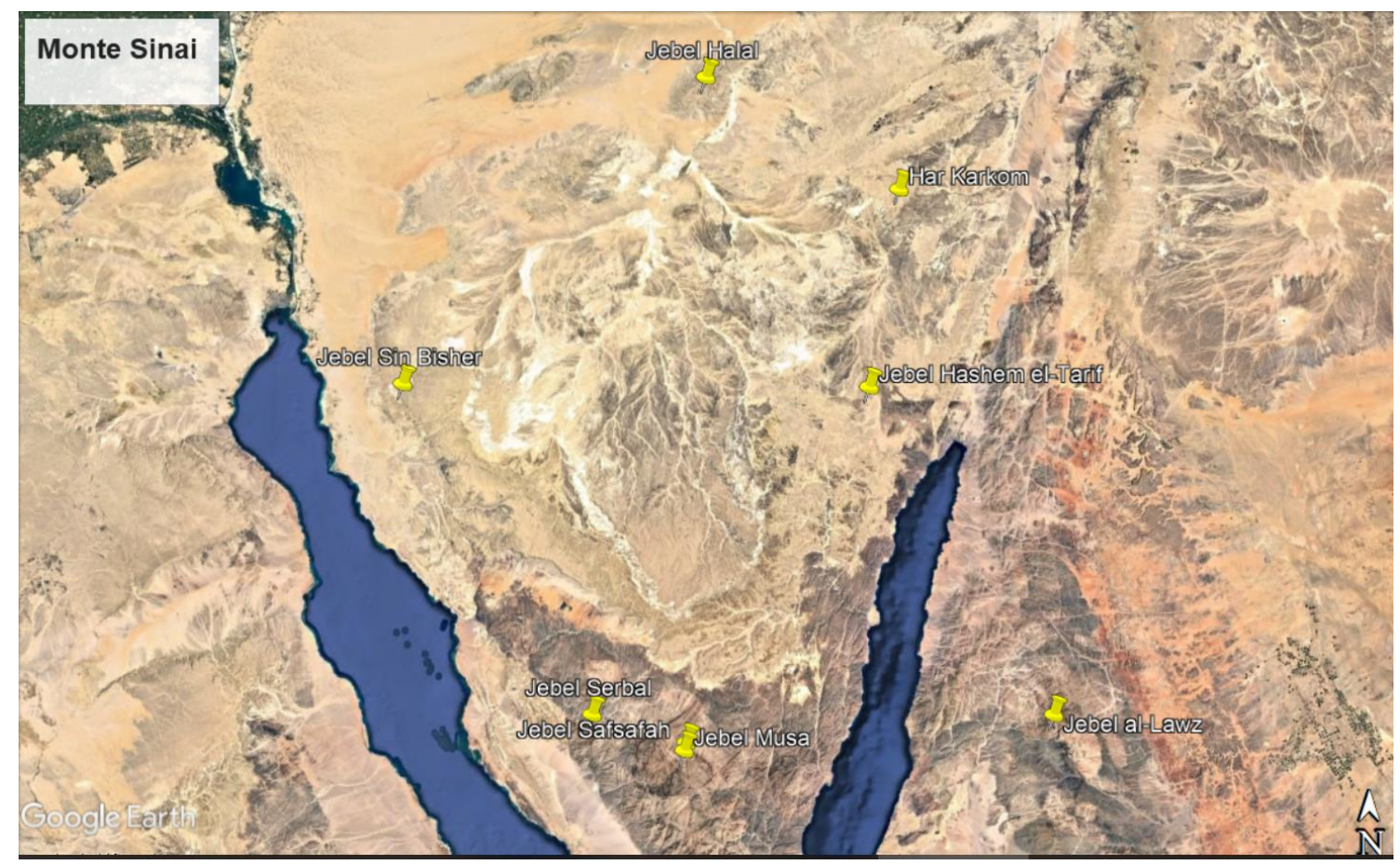

Fig. 1. Possíveis localizações do Monte Sinai (Mapa: Google Earth 2008 - versão 4.3.7284.3916)

Quase todas as possibilidades localizam-se na região central ou sul da Península do Sinai. O Monte Sinai não pode se localizar no norte da península, devido aos seguintes fatores: esta região é muito próxima do "Caminho da Terra dos Filisteus", caminho evitado pelos israelitas ${ }^{78}$; não há, no norte, um “deserto grande e terrível”, devido à proximidade com o Mediterrâneo, nem tampouco a terra montanhosa dos amorreus ${ }^{79}$; não há falta de água no nordeste do Sinai, que é a região mais fértil para a agricultura de toda a península; os israelitas reclamam da falta de peixes ${ }^{80}$, quando próximo à costa do Mediterrâneo e Lago Sirbonis há abundância de locais de pesca; além disso, são onze dias de viagem entre Horebe e CadesBarnéa através do Monte Seir ${ }^{81}$, mas a distância da região norte para Cades-Barnéa é muito curta, além de que o Monte Seir não se localiza nesta região ${ }^{82}$.

\footnotetext{
78 "E aconteceu que, quando Faraó deixou ir o povo, Deus não os levou pelo caminho da terra dos filisteus, que estava mais perto; porque Deus disse: Para que porventura o povo não se arrependa, vendo a guerra, e volte ao Egito. Mas Deus fez o povo rodear pelo caminho do deserto do Mar Vermelho; e armados, os filhos de Israel subiram da terra do Egito" (Ex 13:17-18).

79 "Então partimos de Horebe, e caminhamos por todo aquele grande e terrível deserto que vistes, pelo caminho das montanhas dos amorreus, como o Senhor nosso Deus nos ordenara; e chegamos a Cades-Barnéia" (Dt 1:19). 80 "Lembramo-nos dos peixes que no Egito comíamos de graça..." (Nm 11:5).

81 "São onze dias de viagem desde Horebe, pelo caminho da montanha de Seir, até Cades-Barnéia" (Dt 1:2).

${ }^{82}$ Har-El (1983, p. 415-420).
} 
Inscrições rupestres em vários idiomas podem ser encontradas no Sinai, especialmente em nabateu, árabe, grego e hebraico. Há também, em menor número, inscrições em copta, latim e russo, como também desenhos de barcos, camelos, gazelas, pássaros e jarros ${ }^{83}$.

No Sinai, assim como em Israel (Shechem, Guezer e Laquis), há inscrições de cerca de 1700 A.E.C. ${ }^{84}$, denominadas proto-sinaíticas ou proto-cananéias, que fazem parte dos primórdios da escrita alfabética, ou seja, incluem-se entre as inscrições alfabéticas mais antigas já encontradas. Estas inscrições foram feitas em uma esfinge de arenito por mineiros semitas ocidentais, escravos ou cativos, em Serābîṭ el-Khâdim e descobertas por Sir Flinders Petrie em 1905 (Fig. 2, 3) ${ }^{85}$. A esfinge feminina, modelo de arte egípcia comum após o décimo-quinto século A.E.C., demonstra a familiaridade dos mineiros com a cultura egípcia ${ }^{86}$. Há diversas teorias sobre a origem desta escrita: uma teoria defende que o alfabeto foi inventado em Serābît el-Khâdim por cananeus que não conheciam os hieróglifos egípcios ${ }^{87}$; outra teoria defende que estas inscrições em cananeu, língua semítica ocidental, surgiram possivelmente com alguma influência egípcia ${ }^{88}$; uma terceira teoria defende que estas inscrições representem um estágio da escrita intermediária entre os hieróglifos egípcios e o alfabeto semítico do norte ${ }^{89}$.

A Teoria Proto-Sinaítica sobre a origem da escrita de 1916, criada por Sir Alan Gardiner, baseia-se nestas inscrições. Os autores das inscrições proto-sinaíticas criaram um alfabeto linear, com um número de sinais muito pequeno - menos de trinta, baseado no princípio chamado de acrofonia ("som inicial"): a primeira letra da palavra semítica é o sinal para nomear o objeto do pictograma original. Em semítico ocidental, “casa” era bet, então o pictograma "casa" foi usado para indicar a consoante bet. Este princípio acrofônico pode não explicar todos os sinais ${ }^{90}$.

\footnotetext{
${ }^{83}$ Kawatoko \& Tokunaga (2006, p. 217, 219).

${ }^{84}$ Healey (1996, p. 260-262). Albright (1948b, p. 12) identifica o período das inscrições do Sinai, como também de Shechem, Guezer e Laquis, entre 1800 e 1550 A.E.C.

85 Albright (1948b, p. 13); Healey (1996, p. 260-262). Segundo Albright (1948a, p. 109), “esses documentos constituem, de longe, o corpo de documentos mais antigo de nosso alfabeto ancestral".

${ }^{86}$ Albright (1948b, p. 10, 13).

${ }^{87}$ Goldwasser (2010).

${ }^{88}$ Healey (1996, p. 260-262).

${ }^{89}$ Diringer (1964, p. 35-36).

${ }^{90}$ Healey (1996, p. 260-262). Para saber mais sobre este assunto: GARDINER, Alan H. The Egyptian Origin of the Semitic Alphabet, em: The Journal of Egyptian Archaeology, Sage Publications, Ltd., Vol. 3, No. 1 (Jan., 1916), pp. 1-16; GOLDWASSER, Orly. How the Alphabet Was Born from Hieroglyphs, em Biblical Archaeology Review, Vol. 36, No. 2 (March/April), 2010.
} 


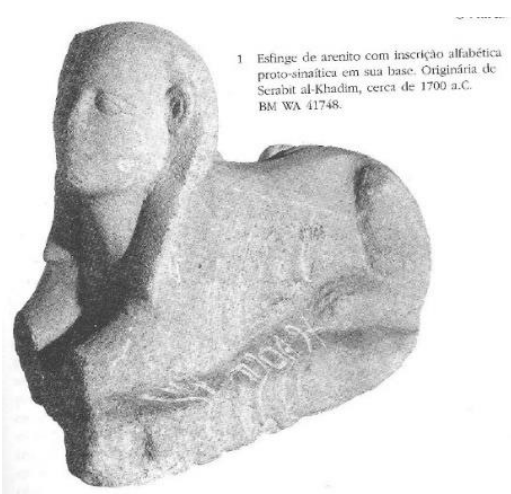

Fig.2. Inscrição proto-sinaítica na base da esfinge, originária de Serābîṭ el-Khâdim, no British Museum, no. 41748 (Healey, 1996, p. 261).

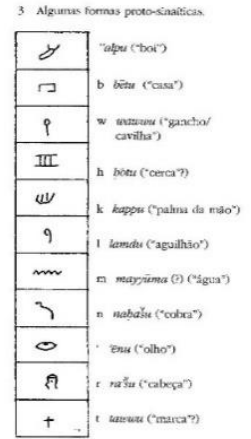

Fig. 3. Algumas formas proto-sinaíticas (Healey, 1996, p. 262).

Tabela completa em Gardiner (1916, p. 4).

A população atual total da Península do Sinai é estimada em 600.000, um terço dos quais chamam a si próprios de beduínos ${ }^{91}$. No sul da península, vivem aproximadamente dez mil beduínos. Moram em vilarejos temporários, em tendas ou cabanas de madeira, como também em locais permanentes, em estruturas de pedra ${ }^{92}$.

Apesar da sua localização e cidadania, os beduínos não se assimilam na cultura egípcia. São vistos pelos demais cidadãos egípcios como incivilizados e desqualificados, com desconfiança e desprezo. Estão entre os mais pobres e marginalizados cidadãos egípcios. Mais de $80 \%$ deles são pobres, passam fome, e não têm acesso à água potável e sistema de saúde. Quase a metade dos adultos (44\%) não possui educação formal. A média de ganho diária é de menos de um dólar por dia por pessoa ${ }^{93}$.

Os beduínos são originariamente pastores seminômades, cuja principal atividade econômica é a criação de pequenos rebanhos de cabras negras de uma raça anã, muito bem adaptadas às condições áridas. Estas cabras podem permanecer por quatorze dias sem água, mesmo perdendo até $40 \%$ do seu peso. Utilizam-se da vegetação rasteira local como pasto. Essa vegetação também é utilizada pelos beduínos como combustível ${ }^{94}$. Além dos pequenos rebanhos de cabras negras, muitos beduínos criam ovelhas e cultivam pomares nos montes mais altos e nos oásis que podem ter tâmaras, maçãs, damascos, amêndoas, marmelos, peras, uvas, ameixas, figos, nozes e amoras. Trigo, apenas em pequenos bolsões de solo aluvial criados pelo escoamento de água das enchentes. Raramente se distanciam mais de cinquenta quilômetros

\footnotetext{
91 Dados do ano de 2013 (Kovač \& Guertin, 2013, p. 2).

92 Beit-Arieh (1988, p. 35).

${ }^{93}$ Gilbert (2011, p. 8, 9, 19, 24). Para mais informações, veja também The South Sinai Foundation, disponível em: <https://www.southsinaifoundation.org/bedu>, acesso em: 15/06/2021.

${ }^{94}$ Beit-Arieh (1988, p. 35).
} 
das fontes de água do verão. A criação de animais é de grande importância para os beduínos, proporcionando leite, queijo, carne, lã para roupas e tapetes e peles para transportar água. Sua dieta é suplementada com peixes e alimentos comprados, como por exemplo, cereais, chá, café, açúcar, óleo e lentilhas. Para ganhar seu sustento, além da agropecuária, os beduínos possuem diversas atividades: trabalham na produção de carvão, transporte por camelos, guias de peregrinos para o Monte Sinai, e eventualmente caça e pesca. Há também registros de beduínos trabalhando no tráfico de drogas ${ }^{95}$ e contrabando. Os beduínos não podiam servir no exército, polícia e outros serviços públicos ${ }^{96}$. Além disso, não possuem representação política, portanto, suas necessidades, direitos e aspirações não são ouvidas pelas autoridades. Mesmo com o número elevado de turistas no Sinai, que chegaram a 2,6 milhões em 2003, mais de um terço do total de turistas em todo o país, os beduínos pouco se beneficiam dessa atividade, que representa $11 \%$ do PIB do Egito. Os milhares de empregos decorrentes do turismo não são ocupados pelos beduínos, que são beneficiados de forma quase insignificante, apenas como guias ou motoristas do deserto ${ }^{97}$.

O departamento de viagens do governo britânico, Foreign and Commonwealth Office, desaconselha quaisquer viagens ao Sinai, como também viagens não essenciais a todo o território egípcio, devido, principalmente, ao terrorismo, motivado pelos conflitos no Iraque e na Síria ${ }^{98}$. Estima-se que dois terços dos ataques terroristas em território egípcio ocorram na Península do Sinai, muitas vezes visando funcionários ou instalações do governo. Grupos radicais no Sinai atraem combatentes estrangeiros, entre eles afegãos, iemenitas, sírios, sauditas, líbios, argelinos e sudaneses, para lutar contra os governos egípcio e israelense. Além disso, há um forte contrabando de armas vindo do Sudão no sul, da Líbia no oeste, e de Gaza no leste, que fortalece a capacidade de atuação dos grupos militantes ${ }^{99}$. Portanto, o Sinai serve como um local de trânsito do tráfico internacional de armas, especialmente do Sudão e da Líbia para Gaza, como também do tráfico de seres humanos, com o apoio de grupos terroristas estrangeiros $^{100}$.

Neste cenário, os beduínos possuem um papel dúbio. Frequentemente, fornecem alguma segurança para pontos industriais e dutos em toda a Península do Sinai, e ajudaram algumas vezes a mediar crises envolvendo diversos grupos militantes. Como exemplo, em 2013, sete

\footnotetext{
95 Gilbert (2011, p. 9-10).

${ }^{96}$ Kovač \& Guertin $(2013$, p. 2).

${ }^{97}$ Gilbert (2011, p. 8, 13, 14).

98 Mais detalhes no site do governo britânico: British Foreign and Commonwealth Office, disponível em: <https://www.gov.uk/foreign-travel-advice/egypt>, acesso em: 15/06/2021.

${ }^{99}$ Chenesseau \& Azzam (2015, p. 91, 93).

${ }^{100}$ Kovač \& Guertin (2013, p. 2).
} 
soldados foram libertados ilesos devido à negociação dos beduínos com os sequestradores ${ }^{101}$. Por outro lado, os jovens beduínos, confrontados com a pobreza e poucas perspectivas de emprego, foram gradualmente influenciados pela ideologia dos grupos terroristas, proporcionando aos radicais refúgio, acesso a recursos locais e rotas de fuga ${ }^{102}$.

Apesar de ter lançado a Operação Sinai em 2012 para combater em larga escala o terrorismo na região, o Egito demonstra incapacidade de manter a lei e a ordem de maneira adequada. Uma força de paz internacional (Multinational Force and Observers - MFO) foi estabelecida durante o acordo de Camp David (1979), que conta atualmente com 1660 soldados de treze países, porém, após sofrer ataques, demonstrou que também carece de autoridade e recursos para engajar e defender com sucesso a península contra os extremistas ${ }^{103}$.

A espantosa escolha do Sinai, árido e inóspito, perigoso e desconfortável, como cenário para alguns dos episódios mais marcantes do Pentateuco, é explicada por uma parábola do Midrash, que compara a altura dos montes à sua soberba - quanto mais alto, mais arrogante. Portanto, a escolha do Sinai deve-se justamente à sua inferioridade. A parábola define a humildade como a característica humana mais desejável de todas, um caminho para alcançar o mérito e a honra.

"A soberba do homem o abaterá" [Pr 29:23a] ${ }^{104}$, é [o Monte] Tabor e [o Monte] Carmel que vieram do fim do mundo, se orgulham de dizer "somos altos e sobre nós Deus outorga a Torá". "Mas o humilde de espírito obterá honra" [Pr 29:23b], esse é [o Monte] Sinai que humilhou-se dizendo "sou baixo" e por isso baixou Deus a Sua honra sobre ele e outorgou sobre ele a Torá e teve mérito de toda esta honra, conforme é dito: "E, tendo o Senhor descido sobre o monte Sinai...” [Ex 19:20 $]^{105}$.

\section{Bibliografia}

AHARONI, Yohanan. The Land of the Bible. A Historical Geography. Philadelphia: The Westminster Press, 1979.

\footnotetext{
${ }^{101}$ Chenesseau \& Azzam (2015, p. 91, 93).

102 Kovač \& Guertin (2013, p. 2).

${ }^{103}$ Dados do ano de 2013 (Kovač \& Guertin, 2013, p. 5).

104 "A soberba do homem o abaterá; mas o humilde de espírito obterá honra" (Pr 29:23).

105 Em hebraico: “

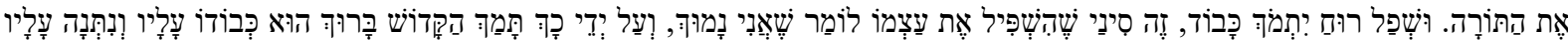
(Midrash Nm Raba 13:3, disponível em: <https://www.sefaria.org/Bamidbar_Rabbah.13.3?lang=bi\&with=all\&lang2=en>， acesso em: 29/11/2021, tradução nossa).
} 
ALBRIGHT, W. F. “Baal-Zephon”: Festschrift Alfred Bertholet Zum 8o. Geburtsag. Turbigen: J. C. B. Mohr, 1950, em: HOFFMEIER, James K. Ancient Israel in Sinai. The Evidence for the Authenticity of the Wilderness Tradition. New York: Oxford University Press, 2005, p. 125.

Exploring in Sinai with the University of California African Expedition, em: Bulletin of the American Schools of Oriental Research, The University of Chicago Press on behalf of The American Schools of Oriental Research, No. 109 (Feb., 1948a), pp. 5-20, disponível em: <https://www.jstor.org/stable/1355842>, acesso em: 29/11/2021.

The Early Alphabetic Inscriptions from Sinai and Their Decipherment, em: Bulletin of the American Schools of Oriental Research, The University of Chicago Press on behalf of The American Schools of Oriental Research, No. 110 (Apr., 1948b), pp. 6-22, disponível em: <https://www.jstor.org/stable/3218767>, acesso em: 29/11/2021.

ALTER, Robert e KERMODE, Frank. Guia Literário da Bíblia. São Paulo: Fundação Editora da UNESP, 1997.

ANATI, Emmanuel. The Riddle of Mount Sinai. Archaeological Discoveries at Har Karkom. Capo di Ponte (Valcamonica, Brescia, Itália): Edizioni del Centro, 2001.

BEIT-ARIEH, Itzhaq. The Route Through Sinai: Why the Israelites Fleeing Egypt Went South, in Biblical Archaeology Review, Vol. 14, No. 03 (1988), pp. 28-37, disponível em: <http://cojs.org/articles/BAR\%201988\%20May-Jun/The\%20Route\%20Through\%20Sin ai.pdf>, acesso em: 23/06/2009.

BEREZIN, Jaffa Rivka. Dicionário Hebraico-Português. São Paulo: Editora Universitária de São Paulo, 1995.

BÍBLIA. Hebraico. Mikraot Guedolot Meorot. Volumes 1 a 5. Jerusalém: Bruchman, 1995.

BÍBLIA. Português. A Bíblia de Jerusalém. 2a Impressão. São Paulo: Paulus, 2003.

BÍBLIA. Português. A Bíblia Sagrada. João Ferreira d’Almeida. Rio de Janeiro: Sociedades Bíblicas Unidas, 1950. 
BÍBLIA. Português. Torá - A Lei de Moisés. Meir M. Melamed. São Paulo: Sefer, 2001.

BRIGHT, John. A History of Israel. Louisville (KY): Westminster John Knox Press, 2000.

BROWN, F.; DRIVER, S. R.; e BRIGGS, C. A. A Hebrew and English Lexicon of the Old Testament. New York: Houghton Mifflin Company/Oxford University Press, 1907.

CHENESSEAU, Thomas; AZZAM, Chantal. Egypt, em: Counter Terrorist Trends and Analyses, International Centre for Political Violence and Terrorism Research, Vol. 7, No. 1 (January/February 2015), pp. 91-95, disponível em: <https://www.jstor.org/stable/10.2307/26351327>, acesso em: $25 / 08 / 2021$.

COLE, R. Dennis. The New American Commentary. Vol. 38 - Numbers. Nashville: Broadman \& Holman Publishers, 2000.

CORNUKE, Robert; HALBROOK, David. In Search of the Mountain of God: The Discovery of the Real Mount Sinai. Nashville (Ten): Broadman and Holman, 2000.

DAVIES, G. I. The Way of the Wilderness: A Geographical Study of the Wilderness Itineraries in the Old Testament, em: The Society for Old Testament Study, Monograph Series No. 5. Cambridge: Cambridge University Press, 2009.

DEUTSCH, Yosef. Let My Nation Go. Jerusalem: Feldheim Publishers, 1998.

Let My Nation Serve Me. New York: Mesorah Publications, 2006.

DIRINGER, David. A História do Álef Bet. Vol. 1. Rio de Janeiro: Biblos, 1964.

ESPINEL, Andrés Diego. Etnicidad y territorio en el Egipto del Reino Antiguo. Colección Avla AEgyptiaca - Studia, Vol. 6. Belaterra (Barcelona): Universitat Autònoma de Barcelona - a Servei de Publicacions, 2006.

FREEDMAN, David N.. The Anchor Bible Dictionary. New York: Doubleday, 1992. 
GARDINER, Alan H. The Delta Residence of the Ramessides, em: The Journal of Egyptian Archaeology, Sage Publications, Ltd., Vol. 5, No. 4 (1918), pp. 242-271, disponível em: <http://www.jstor.org/stable/3853579>, acesso em 22/07/2009.

The Egyptian Origin of the Semitic Alphabet, em: The Journal of Egyptian Archaeology, Sage Publications, Ltd., Vol. 3, No. 1 (Jan., 1916), pp. 1-16, disponível em: <https://www.jstor.org/stable/3853586>, acesso em: 29/11/2021.

GILBERT, Hilary. 'This is not our life, it's just a copy of other people's': Bedu and the price of 'development' in South Sinai, em Nomadic Peoples, White Horse Press Stable, 2011, Vol. 15, No. 2 (2011), pp. 7-32, disponível em: <https://www.jstor.org/stable/43133005>, acesso em: 10/06/2021.

GOLDWASSER, Orly. How the Alphabet Was Born from Hieroglyphs, em Biblical Archaeology Review, Vol. 36, No. 2 (March/April), 2010.

HAR-EL, Menashe. The Sinai Journeys. The Route of the Exodus. San Diego (CA): Ridgefield Publishing Company, 1983.

HASTINGS, James. Dictionary of the Bible. New York: Charles Scribner's Sons, 1909.

HEALEY, John F. O Primeiro Alfabeto, em HOOKER, J. T. Lendo o passado: do cuneiforme ao alfabeto. A história da escrita antiga. São Paulo: Co-edição EDUSP-Melhoramentos, 1996, pp. 245-314.

HIRSCH, Emil G. Wilderness, em: JewishEncyclopedia (2002), disponível em: $<$ http://www.jewishencyclopedia.com/view_friendly.jsp?artid=183\&letter=W>, acesso em 05/07/2009.

HOFFMEIER, James K. Ancient Israel in Sinai. The Evidence for the Authenticity of the Wilderness Tradition. New York: Oxford University Press, 2005.

Israel in Egypt. The Evidence for the Authenticity of the Exodus Tradition. New York: Oxford University Press, 1996. 
HUBNER, M. M. A Rota do Êxodo. 1. ed. São Paulo: Novas Edições Acadêmicas, OmniScriptum GmbH \& Co KG (Saarbrücken, Deutschland), 2016.

ISAACS, Jacob. Our People: History of the Jews. New York: Kehot, 1946.

JARVIS, C. S. Yesterday and Today in Sinai. New York: Houghton Mifflin, 1932.

JASTROW, Marcus [ed.]. A Dictionary of the Targumim, The Talmud Babli and Yerushalmi, and the Midrashic Literature. New York: G. P. Putnam's Sons, 1903.

Jewish Encyclopedia. New York: The Kopelman Foundation, 2002-2011, disponível em: <http://www.jewishencyclopedia.com>.

JOHNSON, Paul. A History of the Jews. New York: Harper Perennial, 1987.

JOSEFO, Flávio. História dos Hebreus. Rio de Janeiro: CPAD, 2008.

Judaic Classics Library - version 2.2. New York: Judaica Press, 2001.

Judaic Classics: The Soncino Talmud. Versão 3.4. New York: Judaica Press, 1990.

KANTOR, Mattis. Codex Judaica: Chronological Index of Jewish History. New York: Zichron Press, 2007.

KAPLAN, Aryeh. The Living Torah. New York: Maznaim Publishing Corporation, 1981.

KAWATOKO, Mutsuo \& TOKUNAGA, Risa. Arabic rock inscriptions of south Sinai Source: Proceedings of the Seminar for Arabian Studies, em: Papers from the thirty-ninth meeting of the Seminar for Arabian Studies held in London, Archaeopress 21-23 July 2005 (2006), vol. 36, pp. 217-227, disponível em: <https://www.jstor.org/stable/41223893>, acesso em: 10/06/2021.

KOEHLER, Ludwig; BAUMGARTNER, Walter [ed.]. Lexicon in Veteris Testamenti Libros. Leiden: E. J. Brill, 1985. 
KOVAČ, Nikolas; GUERTIN, Trista. Armed Groups in the Sinai Peninsula, em: Enschede: Civil Military Fusion Centre, 2013, disponível em: <https://reliefweb.int/sites/reliefweb.int /files/resources/20130228\%20Armed\%20Groups\%20in\%20the\%20Sinai\%20Peninsula.pdf>, acesso em: 23/11/2021.

KITCHEN, Kenneth A. On the reliability of the Old Testament. Grand Rapids (Michigan): William B. Eerdmans Publishing Company, 2006.

LEVINE, Baruch A. The Anchor Bible. Numbers 21-36. New York: Doubleday, 2000.

MAZAR, Amihai. Arqueologia na Terra da Bíblia: 10.000-586 A.E.C. São Paulo: Paulinas, 2003.

MAZAR, Biniamin. Enciclopedia Mikrait (Hebraico). Jerusalém: Bialik Institute, 1982.

MILGROM, Jacob. Numbers. The JPS Torah Commentary. Philadelphia: The Jewish Publication Society, 1996.

Modis: The Near East, in Visible Earth - A Cathalog of NASA Images and Animations of Our Home Planet, disponível em: <http://veimages.gsfc.nasa.gov//1412/ NearEast2.A2000254.0840_md.jpg>, acesso em: 25/02/2008.

NEUSNER, Jacob. Introduction to Rabbinic Literature. New York: The Anchor Bible Reference Library/Doubleday, 1994.

PALMER, E. The Desert of the Exodus: Jorneys on Foot in the Wilderness of the Forty Years' Wanderings. New York: Harper \& Brothers Publishers, 1872. PETRIE, W. M. F. Researches in Sinai. New York: E. P. Duton, 1906.

PRENTICE, Jr. Sartell. The Route of Israel in the Desert, em: The Biblical World, Vol. 41, No. 4. (1913), pp. 238-244, disponível em: <http://links.jstor.org/sici?sici=0190- 
3578\%28191304\%2941\%3A4\%3C238\%3ATROIIT\%3E2.0.CO\%3B2-2>, acesso em $15 / 03 / 2007$.

PRITCHARD, James B. [ed.]. The Ancient Near East: An Anthology of Texts \& Pictures. Princeton (NJ): Princeton University Press, 2011.

PROCOPIUS. Vol. 7. Trad. H. B. Dewing. Cambridge, MA: Harvard University Press, 1971.

RUDNITZKY, Arik. The Bedouin Population in the Negev. The Abraham Fund Initiatives, 2012.

SACKS, Jonathan. Uma Letra da Tora. São Paulo: Sefer, 2002.

SARNA, Nahum M. Exodus. The JPS Torah Commentary. Philadelphia: The Jewish Publication Society, 1996.

Exploring Exodus: The Origins of Biblical Israel. New York: Schoken Books, 1996.

SCHWARTZ, Dan. Eleh Mas'ei. Jerusalem: Dan Schwartz, 2003.

TEAGUE, Matthew. The Sinai's Separate Peace, em: National Geographic, Vol. 215, No. 3 (2009), pp. 98-121.

WYATT, Ronald; FASOLD, David. Anchor Stone International, disponível em: $<$ http://anchorstone.com/real-mt.-sinai/newsletter-06-january-1994.html>, acesso em: 30/06/2009. 